\title{
CAPACIDADES ESTATAIS E POLÍTICAS PÚBLICAS: O PAPEL DA CAPACIDADE POLÍTICO-RELACIONAL NO DESENVOLVIMENTO DO PRONAF ${ }^{1}$
}

\author{
STATE CAPABILITIES AND PUBLIC POLICIES: THE ROLE OF THE \\ POLITICAL-RELATIONAL CAPABILITY IN THE DEVELOPMENT OF \\ PRONAF
}

\section{CAPACIDADES ESTATALES Y POLÍTICAS PÚBLICAS: EL PAPEL DE LA CAPACIDAD POLÍTICA-RELACIONAL EN EL DESARROLLO DE PRONAF}

\author{
Gabriela Solidario de Souza Benatti ${ }^{2}$ \\ https://orcid.org/0000-0002-1594-9919 \\ Antônio Márcio Buainain ${ }^{3}$ \\ https://orcid.org/0000-0002-1779-5589
}

Submissão: 29/04/2020 / Aceito: 09/08/2020.

\begin{abstract}
RESUMO
A abordagem das capacidades estatais refere-se aos instrumentos, às aptidões e aos complexos arranjos institucionais de que dispõe o Estado para realizar iniciativas em prol do desenvolvimento socioeconômico. Essa abordagem, que contribui para análises relacionadas à formulação, à implementação e ao desenvolvimento de políticas públicas, ainda foi pouco utilizada para os estudos relacionados ao desenvolvimento rural no Brasil. Este trabalho se concentra na capacidade político-relacional: a habilidade do Estado em criar e expandir canais de conexão com os diversos atores de interesse da sociedade. Como uma das principais iniciativas voltadas ao desenvolvimento rural no Brasil, o Programa Nacional de Fortalecimento da Agricultura Familiar (Pronaf) será utilizado como experiência para verificação do desenvolvimento dessa capacidade desde sua criação, em 1996. A hipótese é a de que a capacidade político-relacional sempre esteve presente no desenvolvimento do Pronaf, motivando a criação do programa e exercendo influência em suas transformações. A metodologia utilizada envolve dois eixos: (i) revisão da bibliografia que trata das temáticas abordadas e (ii) entrevistas com especialistas. Assim, busca-se contribuir para a discussão inovadora sobre as capacidades estatais, bem como para a reflexão acerca do papel dos diferentes grupos de interesse da sociedade no desenvolvimento do Pronaf ao longo dos anos. Palavras-chave: Capacidades estatais. Desenvolvimento rural. Estado. Políticas públicas. Pronaf.

1 - O presente trabalho foi realizado com apoio da Coordenação de Aperfeiçoamento de Pessoal de Nível Superior - Brasil (CAPES) - Código de Financiamento 001.

2 - Mestra em Desenvolvimento Econômico pela Universidade Estadual de Campinas (Unicamp), doutoranda em Desenvolvimento Econômico na Unicamp (Núcleo de Economia Agrícola e do Meio Ambiente NEA/Instituto de Economia), Campinas, São Paulo, Brasil. Email: gssbenatti@ gmail.com .

3 - Professor Doutor no Instituto de Economia da Universidade Estadual de Campinas (Unicamp), pesquisador do Núcleo de Economia Agrícola e do Meio Ambiente - NEA do Instituto de Economia da Unicamp, Campinas, São Paulo, Brasil. Email: buainain@gmail.com .
\end{abstract}




\begin{abstract}
The State capabilities approach refers to the instruments, skills and complex institutional arrangements which are connected to make possible to the State to carry out initiatives for socio-economic development. This approach, certainly rich, has been not widely used for studies related to rural development in Brazil. This work focuses on the political-relational capability, which is the State's ability to create and expand connection channels with the various stakeholders of society. As one of the main initiatives for rural development in Brazil, the National Program for Strengthening Family Farming (Pronaf) will be used as an experience to verify the development of this capability dimension since its creation, in 1996. The hypothesis is: political-relational capability was always strongly present in the development of Pronaf, motivating the creation of the program and influencing transformations over time. The methodology used involves two axes: i) review of the bibliography that deals with the topics covered, and ii) interviews with specialists. Thus, the aim of this work is to contribute to the innovative discussion on State capabilities, as well as to a reflection about the role of the stakeholders in Pronaf's development over time.
\end{abstract}

Keywords: Pronaf. Public policies. Rural development. State. State capabilities.

\title{
RESUMEN
}

El enfoque de las capacidades estatales se refiere a los instrumentos, habilidades y arreglos institucionales complejos disponibles para que el Estado lleve a cabo iniciativas a favor del desarrollo socioeconómico. Este enfoque, ciertamente rico, todavía era poco utilizado para estudios relacionados con el desarrollo rural en Brasil. Este trabajo se centra en la capacidad político-relacional: la capacidad del Estado para crear y expandir canales de conexión con los diversos actores de interés para la sociedad. Como una de las principales iniciativas dirigidas al desarrollo rural en Brasil, el Programa Nacional para el Fortalecimiento de la Agricultura Familiar (Pronaf) se utilizará como una experiencia para verificar el desarrollo de esta capacidad desde su creación en 1996. La hipótesis es que la capacidad políticarelacional siempre ha estado fuertemente presente en el desarrollo de Pronaf, motivando la creación del programa e influyendo en los cambios a lo largo del tiempo. La metodología utilizada involucra dos ejes: i) revisión de la bibliografía que trata los temas tratados, y ii) entrevistas con especialistas. Por lo tanto, busca contribuir a la discusión innovadora sobre las capacidades estatales, así como a una reflexión sobre el papel de los diferentes grupos de interés de la sociedad en el desarrollo de Pronaf a lo largo del tiempo.

Palabras clave: Capacidades estatales. Desarrollo rural. Estado. Políticas públicas. Pronaf.

\section{INTRODUÇÃO}

O Estado é um ator importante na promoção do desenvolvimento e sua atuação historicamente foi objeto de intensos debates. A literatura sobre capacidades estatais chama a atenção para a importância de determinados conjuntos de capacidades para o desempenho de funções gerais e específicas. O foco não se limita ao papel do Estado como criador de políticas públicas, mas à relação entre Estado, instituições, organizações, setores e sociedade, 
que possam sustentar uma estratégia para alcançar as vias de desenvolvimento desejadas (BOSCHI, 2018). Essa abordagem, que contribui para análises relacionadas à formulação, à implementação e ao desenvolvimento de políticas públicas, ainda é pouco aplicada nos estudos relacionados ao desenvolvimento rural no Brasil, o que foi uma das motivações para sua utilização como foco deste trabalho.

O conceito de capacidades estatais é abrangente, complexo e multidisciplinar. A capacidade político-relacional, especificamente tratada neste artigo, refere-se às habilidades do Estado em criar e expandir os canais de inclusão, interlocução e negociação com os diversos atores da sociedade, processando conflitos e prevenindo o direcionamento de suas decisões a interesses específicos (GOMIDE, 2016; IDB, 2006). No Brasil, o Programa Nacional de Fortalecimento da Agricultura Familiar (Pronaf) destaca-se como uma das principais iniciativas voltadas ao desenvolvimento rural, o que justifica sua escolha para ser utilizado como experiência na verificação do desenvolvimento da dimensão da capacidade político-relacional.

Assim, este artigo não se propõe realizar uma análise do Pronaf, mas tem como objetivo geral verificar a influência e a força da capacidade político-relacional no programa desde sua criação, em 1996. A pergunta que moveu este trabalho foi a seguinte: qual foi o papel da capacidade político-relacional no desenvolvimento do Pronaf desde sua criação? Com base nesse problema de pesquisa, uma hipótese, que pareceu relevante para orientar as reflexões, emergiu: a capacidade político-relacional sempre esteve presente no desenvolvimento do Pronaf, motivando a criação do programa e exercendo influência nas transformações ao longo dos anos.

O trabalho está estruturado em cinco partes, incluindo esta introdução. O item "Fundamentação teórica" tem como objetivo apresentar o contexto histórico de surgimento da abordagem teórica de capacidades estatais e sua conceituação. Em seguida, expõe-se a metodologia deste trabalho. A parte intitulada "A capacidade político-relacional no âmbito do Pronaf" aborda o desenvolvimento e a influência da capacidade estatal no programa desde a sua criação. A última seção elenca algumas considerações finais. 


\section{FUNDAMENTAÇÃO TEÓRICA: A ABORDAGEM DAS CAPACIDADES ESTATAIS}

O papel do Estado na economia e na sociedade é foco de muitos debates, com base em diferentes teorias. As discussões relacionadas especificamente às capacidades estatais estão presentes no âmbito internacional desde a década de 1980, quando a instabilidade financeira e os altos índices de pobreza e desemprego verificados em diversos países ressaltaram a necessidade de um Estado mais atuante, capaz de lidar com esses problemas. Mas foi após a crise de 2008-2009 que ganhou força a importância das capacidades estatais para a instituição executar o script que lhe cabe, cumprindo funções imprescindíveis (BOSCHI, 2018; GOMIDE, 2016).

Com base na experiência dos últimos 50 anos, é possível fazer pelo menos duas afirmações: (i) o Estado é um ator fundamental para promover o desenvolvimento sustentável e para construir estruturas socioeconômicas mais eficientes, equilibradas e equitativas, e (ii) as capacidades do Estado são limitadas. Nesse sentido, é importante compreender as competências que o Estado possui e deve possuir para promover ações em prol do desenvolvimento socioeconômico. Além disso, é necessário reconhecer o papel dos arranjos institucionais, que devem atuar de maneira inter-relacionada e coordenada. Assim, a abordagem das capacidades estatais não se restringe ao Estado, como ator monolítico, mas considera outros atores, públicos ou privados, que se relacionam com essa instituição e cooperam em prol de determinados objetivos em comum.

Boschi e Gaitán (2008), bem como Boschi e Diniz (2013), ressaltam que as capacidades se relacionam às habilidades da burocracia estatal para implementar as metas oficiais. Desse modo, simplificadamente, o conceito de capacidade estatal pode ser considerado como "o conjunto de instrumentos e instituições de que dispõe o Estado para estabelecer objetivos, transformá-los em políticas e implementá-las” (SOUZA, 2016, p. 51). As capacidades específicas do Estado são um conjunto de aptidões que variam no tempo e também por área de atuação. Ou seja, um Estado pode ter contado com muita capacidade administrativa no passado e ter perdido essa capacidade pelas mudanças no sistema político ou pela fragilização da burocracia, por exemplo (SCARTASCINI; TOMMASI, 2014). 
Do ponto de vista das dimensões de capacidade, muitas podem ser destacadas, como a de financiamento, que se relaciona com a arrecadação de recursos e a alocação eficiente do orçamento para a execução de políticas públicas, a capacidade burocrática, que se refere à administração pública responsável por operacionalizar as iniciativas e as aptidões técnicas dos agentes que são parte dessa burocracia, ou a capacidade político-relacional, que é o foco deste trabalho. Esta última capacidade depende da articulação entre o Estado e a sociedade, e refere-se às habilidades da burocracia estatal em criar e expandir os canais de inclusão, interlocução e negociação com os diversos atores da sociedade, mediando conflitos e prevenindo a captura das ações públicas por interesses específicos (CINGOLANI, CROMBRUGGHE, THOMSSON, 2013; EVANS, 2011).

A capacidade político-relacional reflete também a aptidão dos governos em mobilizar recursos políticos, prestar contas e internalizar informações necessárias para a efetividade de suas ações. Essa dimensão depende fortemente da existência e da operação efetiva de formas de participação social (conselhos, conferências, ouvidorias, audiências e consultas públicas, entre outras). Quando esse tipo de interlocução comunicativa entre Estado e sociedade ocorre, o cidadão ativo tem a oportunidade de participar dos processos de discussão e deliberação sobre as demandas sociais, criando possíveis respostas às demandas existentes (FARIA; FONTANA, 200-?; GRISA; SCHNEIDER, 2014).

Os atores podem influenciar na construção das políticas de múltiplas maneiras, até mesmo por meio de relações informais e pessoais. Essa influência envolve processos de conflito e de consenso, o que configura uma arena política. Do ponto de vista da arena política, esses atores são usualmente classificados em grupos formais e informais, ambos igualmente importantes em termos de influência. Entre os grupos formais, mencionam-se como exemplos partidos políticos, presidentes, gabinetes, legislaturas, tribunais e burocracia; seus papéis de formulação de políticas são formalmente designados na constituição. Entre os grupos informais, exemplos são os movimentos sociais, que não têm papéis formais designados, mas contam com o direito de expressar suas demandas e, assim, influenciam nas tomadas de decisão (FREY, 2000; IDB, 2006). Portanto o bom desenvolvimento da capacidade político-relacional depende de contextos democráticos, abertos e interessados no diálogo com a sociedade. 
Sem o exercício da democracia, formas organizadas de participação social com poder político não seriam possíveis ou não teriam relevância para as decisões do governo. $\mathrm{O}$ exercício dessa capacidade tende a ser desafiador em contextos em que esse tipo de governo é recente, que sofre diversas ameaças continuamente por propostas extremistas, autoritárias e conservadoras e que carregam passado de autoritarismo, clientelismo e populismo, como na América Latina (IDB, 2006).

\section{METODOLOGIA}

A metodologia utilizada para a verificação do papel da capacidade político-relacional no Pronaf envolve dois eixos: (i) revisão bibliográfica e (ii) entrevistas não estruturadas com 13 especialistas $^{4}$ que acompanharam de perto a criação e o desenvolvimento do Pronaf e relataram suas experiências e pontos de vista sobre a evolução do programa desde a sua criação.

A seleção da literatura foi realizada nas bases de dados SciELO, Scopus e Web of Science. Em relação às entrevistas, selecionaram-se os entrevistados pela sua formação e atuação profissional, incluindo profissionais que ocuparam cargos do governo federal e estadual, com experiência em pesquisa e consultoria com movimentos sociais e agências de cooperação internacional, além de experiência acadêmica e contato com diferentes políticas públicas. Para informações detalhadas sobre os entrevistados, consultar Benatti (2018).

\section{A CAPACIDADE POLÍTICO-RELACIONAL NO ÂMBITO DO PRONAF}

O objetivo desta seção é demonstrar as relações do Estado brasileiro com o públicoalvo do Pronaf, os agricultores familiares, desde a criação do programa, já que movimentos sociais a impulsionaram. Ao longo dos anos, as relações com os agricultores familiares e suas organizações motivaram transformações no programa, pelas demandas desses atores,

\footnotetext{
${ }^{4}$ Este trabalho é parte de um projeto maior, uma dissertação de mestrado, que trata de outras dimensões de capacidades estatais e de discussões que não fazem parte do escopo deste artigo. Para informações detalhadas sobre os entrevistados e a metodologia, consultar Benatti (2018). Decidiu-se não entrar em detalhes neste artigo, por conta da limitação de espaço, pois detalhes importantes poderiam deixar de ser mencionados.
} 
alinhadas também aos objetivos dos formuladores da política. Em suma, as subseções a seguir apresentam o processo de construção e desenvolvimento da capacidade político-relacional no âmbito do Pronaf.

\section{Relação Estado-sociedade no reconhecimento da agricultura familiar brasileira}

O Pronaf foi criado para corresponder às demandas sociais que emergiram a partir da redemocratização do país, simbolizada pela Constituição de 1988. Na década de 1990, as reivindicações dos trabalhadores rurais, destacando-se com as Jornadas Nacionais de Luta e com o Grito da Terra Brasil, ganhavam força no cenário político. Ademais, os estudos realizados pela Organização das Nações Unidas para Agricultura e Alimentação (FAO) e pelo Instituto Nacional de Colonização e Reforma Agrária (Incra) ressaltavam a importância das políticas voltadas à agricultura familiar e ao desenvolvimento rural brasileiro (considerando as necessidades dos diferentes grupos da agricultura familiar brasileira, muito heterogênea). Essas iniciativas trouxeram o foco para a discussão dos pequenos agricultores e de como os incluir com efetividade nas políticas agrícolas e de desenvolvimento rural (BIANCHINI, 2015; GUANZIROLI et al., 2019; MEDEIROS; PICOLOTTO, 2016; SCHNEIDER, 2010; FAVARETO, 2006).

Destacaram-se nesses movimentos bases de representação política, como a Central Única dos Trabalhadores (CUT), criada em 1983, e, nela, o Departamento Nacional de Trabalhadores Rurais (DNTR), criado em 1988; o Movimento dos Trabalhadores Sem Terra (MST), criado em 1984; o Movimento dos Atingidos por Barragens (MAB), institucionalizado em 1991; e o Conselho Nacional dos Seringueiros (CNS), criado em 1985 (GRISA; SCHNEIDER, 2014).

Cazella, Mattei e Schneider (2004) ressaltam que, nos anos 1990, os movimentos sindicais dos trabalhadores rurais direcionaram as reivindicações para uma reconversão e reestruturação produtiva dos agricultores familiares, que seriam afetados principalmente pelo processo de abertura comercial da economia, na ocasião, influenciado pela criação do Mercado Comum do Sul (Mercosul). Nesse período, ocorreram diversas iniciativas políticas comandadas pela Confederação Nacional dos Trabalhadores na Agricultura (Contag) e pelo departamento rural da CUT, o que originou a Federação dos Trabalhadores e Trabalhadoras 
na Agricultura Familiar (Fetraf) (NAVARRO, 2010). Tendo em vista o acirramento das tensões sociais no campo e a necessidade de se colocar em pauta temas do desenvolvimento rural, em 1994, o governo Itamar Franco criou o Programa de Valorização da Pequena Produção Rural (Provap), totalmente reformulado em 1995, gerando o Pronaf.

O Pronaf foi criado em um contexto no qual os agricultores familiares enfrentavam grandes dificuldades no financiamento de seu custo de produção, o que foi agravado pela falta histórica de acesso ao crédito rural oficial e pelas dificuldades associadas à implementação do Plano Real, que implicou forte restrição nas despesas do governo, valorização cambial e redução das tarifas de importação de alimentos básicos - que representavam os principais itens produzidos por esse grupo. Eles também enfrentavam dificuldades em expandir sua capacidade produtiva por meio da adoção de inovações tecnológicas. Para superar esses gargalos, o Pronaf buscou estimular o investimento produtivo e fornecer às famílias capital de giro, levando em consideração a diferenciação entre agricultores familiares e a necessidade de apoio especial ao grupo mais vulnerável. As famílias de baixa renda teriam acesso ao crédito com taxas de juros mais baixas e com melhores condições. De um modo geral, as taxas de juros operadas pelo programa sempre foram inferiores às operadas pelo mercado (GUANZIROLI et al., 2019).

As criações do Ministério do Desenvolvimento Agrário (MDA), em 1999, e da Secretaria da Agricultura Familiar (SAF), em 2001, representaram a institucionalização dessas temáticas no interior da burocracia estatal (BIANCHINI, 2015). Em 2006, regulamentou-se a Lei $\mathrm{n}^{\mathrm{o}} 11.326$, que reconheceu a agricultura familiar como categoria social, definiu sua estrutura conceitual e passou a orientar as políticas públicas para essa categoria social, representando seu reconhecimento pelo Estado brasileiro (BRASIL, 2006). A criação do Plano Safra da agricultura familiar bem como um Censo Agropecuário com um caderno específico com resultados da agricultura familiar - como foi o caso do volume de 2006 - são outros indícios de reconhecimento da categoria em nível nacional e da ampliação do seu destaque no Brasil, em grande parte relacionado às preocupações com o desenvolvimento rural.

No caso brasileiro, o critério de delimitação territorial de quatro módulos fiscais na definição de estabelecimento familiar correspondeu às discussões e às propostas realizadas pelas representações sindicais dos agricultores familiares, como a Fetraf e a Contag 
(MEDEIROS; PICOLOTTO, 2016). Navarro e Pedroso (2011) argumentam que o tamanho de área previsto em lei não tem justificativas econômicas, mas sim político-sindicais, que são legítimas e indicam a força da capacidade político-relacional dos atores de interesse. Além disso, Navarro e Pedroso (2011) ressaltam que a exigência da predominância de mão de obra da própria família no estabelecimento determinada na Lei $\mathrm{n}^{\circ} 11.326$ corresponde também aos interesses político-sindicais, na medida em que predominou uma visão marxista da vida social, de modo que garantisse que não existiria a exploração do trabalho assalariado ou a apropriação da mais-valia.

Pode-se afirmar, então, que o Pronaf se diferencia de outras políticas públicas pois contou, desde sua criação, com a articulação entre ampla coalizão de forças. No início dos anos 1990, em meio a uma crise econômica muito forte e consequente revisão do sistema de crédito por conta de limitações fiscais, os pequenos produtores reivindicavam uma política diferenciada. Em relação à formulação da Lei $n^{\circ} 11.326$, que estabelece diretrizes para a formulação da política nacional voltada à agricultura familiar, grupos sociais também manifestaram suas demandas e influenciaram nas decisões. Esse contexto reflete a força da capacidade político-relacional, que foi muito importante para o sucesso do programa e seu desenvolvimento ao longo de mais de 20 anos.

\section{Mudanças das linhas de crédito ao longo do tempo e algumas implicações}

O Pronaf é composto de grupos de crédito segmentados e orientados a diferentes perfis de agricultores familiares. A segmentação advém do reconhecimento da grande heterogeneidade que envolve o universo da agricultura familiar brasileira e, portanto, das suas diferentes necessidades. Ademais, uma característica marcante desde sua criação foi a preocupação em evitar a reprodução de desigualdades no interior do programa, desigualdades, estas, que marcaram as políticas até então implementadas no meio rural: iniciativas excludentes, concentradoras e conservadoras (AQUINO; SCHNEIDER, 2010; GUANZIROLI et al., 2019).

Ao longo de sua existência, o programa passou por diversas transformações, a maioria refletindo a busca de legitimação política e o aprimoramento técnico, equilíbrio nem sempre possível. De um lado, como os grupos de interesse em torno da agricultura familiar não têm 
visões homogêneas e, em alguns casos, disputam posições conflitivas, acertos com um grupo não raramente se traduziram em desaprovação de outros, o que exigia novas ações para manter a base de apoio. De outro, ainda que os técnicos tenham sempre procurado respaldar as mudanças no discurso do aprimoramento, da eficácia e da eficiência, o fato é que nem sempre foi possível conciliar o aperfeiçoamento com o atendimento das pressões oriundas da base de apoio.

Uma mudança importante foi a que redefiniu os grupos de crédito. Quando o programa foi lançado, os grupos eram A, B, C e D. Em 2004, incluiu-se o grupo E, e, em 2008, unificaram-se as linhas C, D e E em um mesmo grupo (PIRES, 2013). Ao longo dos últimos 24 anos, foram feitos vários ajustes; em 2020, a classificação do programa divide-se nos segmentos A, B e A/C, além de um grupo de renda variável (BACEN, 2019). Várias podem ter sido as motivações para as mudanças, mas, segundo os relatos coletados nas entrevistas, é possível afirmar que prevaleceu a ideia de simplificação para operacionalizar os financiamentos tanto para o MDA como para o Banco do Brasil, principal instituição financeira responsável por operacionalizar o programa.

As mudanças corresponderam também às demandas dos grupos de interesse no sentido de tornar o acesso ao programa mais ágil e adequado às necessidades de grupos específicos de agricultores familiares. Exemplo disso foi a atuação do MDA na trajetória do grupo B, voltado aos agricultores familiares mais vulneráveis. A desburocratização operacional, o estímulo aos bancos trabalharem com esse tipo de crédito (que envolve elevados riscos financeiros e operacionais), o afrouxamento de algumas exigências aos produtores e a incorporação de preocupações relacionadas à capacitação para melhor uso do crédito (microcrédito produtivo orientado) são exemplos desses esforços, que se desenvolveram ao longo da trajetória do programa. Essas medidas contribuíram para ampliar o acesso de famílias de baixa renda ao crédito rural e promover mais qualidade e assistência na aplicação dos recursos (BIANCHINI, 2015; MENDONÇA, 2008).

A estratificação em grupos é um exemplo de rompimento do consenso sobre a necessidade de diferenciação da política, que também garantia o alinhamento político dos movimentos aos vários grupos. Ainda na década de 1990, quando foram estratificados os grupos, até 2004, com a criação do grupo E, a questão da diversificação parecia estar fortemente em pauta. Contudo, como os financiamentos eram baixos nessas diversas linhas, 
surgiu a proposta, tornada regra, de eliminar os grupos, baixar as taxas de juros (na época, passou a vigorar a de $2 \%$ para investimento) para todos e dar-lhes o mesmo tratamento com base em um conceito único. Nesse sentido, o consenso inicial de segmentação foi substituído pelo de unificar os grupos, partindo de uma estratégia de melhoramento da operacionalização do programa, além de redução de custos de transação e de monitoramento (CORREA; SILVA, 2007).

Nas entrevistas, evidenciou-se que, do ponto de vista técnico, como os valores eram muito baixos, o fato de estarem em um único grupo agricultores bastante heterogêneos era insignificante. No entanto, à medida que a agricultura familiar foi demandando mais recursos, especialmente para atender os mais capitalizados, a situação mudou. Com a pressão para ajustar os valores e os limites de financiamento, reintroduziu-se a discussão sobre os grupos, porque a elevação dos valores de financiamento possibilitava a ocorrência de desvios. Essa discussão gerou divergências entre o Ministério da Fazenda e o MDA, principalmente para verificar se caberia ampliar o Pronaf de forma significativa para atender ao público mais estruturado ou se caberia a este público entrar em um programa de médio produtor, como o Programa Nacional de Apoio ao Médio Produtor Rural (Pronamp).

\section{Movimentos sociais e seus reflexos no Pronaf: a segmentação de linhas de crédito}

Além dos grupos de crédito anteriormente citados, criaram-se também novas linhas e sublinhas específicas de financiamento do Pronaf (como agroindústria, mulher, jovem, floresta, semiárido, agroecologia e sustentabilidade ambiental) para atender às demandas específicas de determinados segmentos de agricultores familiares das diversas regiões do país e seus representantes. Assim, o Pronaf ampliou-se na tentativa de tornar-se mais inclusivo e responder a alguns problemas do público-alvo, mas também para atender aos grupos de pressão no interior dos movimentos sociais.

Grupos de jovens entre 16 e 29 anos passaram a contar, desde 2003, com o Pronaf Jovem, que teoricamente dialogava com a questão da sucessão familiar e procurava criar alternativas para os jovens rurais, dialogando também com mobilizações de atores identificados com as pautas jovens, especialmente Contag e Fetraf (BARCELLOS, 2017). O grupo de mulheres, que se destaca na militância rural sobretudo com a Marcha das 
Margaridas, beneficiou-se com o Pronaf Mulher, criado em 2003, buscando trazer protagonismo às mulheres na atividade, tradicionalmente masculina, e também como uma tentativa de empoderamento e manutenção das mulheres no campo. A Marcha das Margaridas entrega a cada edição um documento para o governo federal contemplando sua plataforma política e pauta de reivindicações, que são objeto de análise e resposta por parte do governo. Além disso, representantes do movimento dialogam com o Estado com reuniões e negociações que fazem parte da agenda das Margaridas em Brasília (TRANSFORMATÓRIO..., 20--?; IPEA, 2013).

Os pescadores tradicionais também conquistaram seu espaço no Pronaf como público beneficiário e incluído na categoria agricultura familiar pela organização em movimentos sociais, especialmente com o Movimento de Pescadores e Pescadoras Artesanais (MPP) e o Movimento dos Atingidos por Barragens (MAB). Com forte presença de representantes ribeirinhos, quilombolas e indígenas, esses movimentos buscam a defesa de seus territórios e do meio ambiente, além da garantia de direitos sociais e luta por condições adequadas para produzir e viver com dignidade (CORRÊA, 2009; CPP, 20--?; QUEIROZ, 2015; MAB, 2011). As comunidades quilombolas, especificamente, contam com a Coordenação Nacional de Articulação das Comunidades Negras Rurais Quilombolas (Conaq), criada em 1996. A luta desse grupo, que envolve a garantia de uso coletivo do território e a implantação de projetos de desenvolvimento sustentável e de políticas públicas que levem em consideração a organização das comunidades de quilombo ${ }^{5}$, foi muito importante para o reconhecimento de povos tradicionais como público beneficiário do Pronaf a partir de 2001 e incluído na categoria agricultura familiar (CONAQ, 20--?; SILVA, 2018).

Os povos indígenas contam com diversas representações, como o Conselho Indigenista Missionário (CMI), criado em 1972, a Mobilização Nacional Indigenista ou a Articulação dos Povos Indígenas do Brasil. São muitas as organizações e instituições envolvidas na luta pelos direitos dos povos indígenas, sobretudo a luta por seus territórios e meio de vida. Havia expectativas e interesse do MDA em discutir a cobertura do Pronaf aos povos indígenas, especialmente por conta das demandas na Região Nordeste. Esse grupo foi

\footnotetext{
${ }^{5}$ O Movimento Nacional das Comunidades Negras Rurais Quilombolas, organizado pela Conaq, é considerado um dos mais ativos agentes do movimento negro no Brasil. Unidos pela força da identidade étnica, os quilombolas organizam-se para lutar em prol de seus direitos, especialmente o território, e representam uma história de resistência.
} 
incluído no programa em 2001 (MNI, 2017; APIB, 2005; SOUZA, 2005). Os povos extrativistas também têm representação importante, como o Conselho Nacional das Populações Extrativistas (CNS), criado em 1985, que representa trabalhadores agroextrativistas organizados em associações, cooperativas e sindicatos. Essa representação foi importante para que as demandas desse grupo pudessem ser ouvidas e incorporadas no programa já em 1997 (CNS, 20--?; SOUZA, 2005).

Esses movimentos representam a prática da democracia, do direito à liberdade de expressão e manifestação. Sem sombra de dúvidas, garantem representatividade e voz para grupos minoritários e fragilizados, de modo que estes possam expressar suas demandas. Cabe ao Estado reconhecer e interpretar essas demandas, colocando em pauta discussões que se relacionem com as necessidades desses grupos. Os formuladores de políticas devem verificar a melhor forma de incorporar tais demandas, traduzindo os processos de conflito e consenso em respostas às necessidades sem colocar em xeque aspectos como estabilidade ou eficiência da política pública. Essa, contudo, não é tarefa simples: as entrevistas destacaram a dificuldade na relação entre os diferentes grupos na agricultura, na medida em que há um choque muito grande entre as diferentes organizações e instituições ${ }^{6}$. A fragilidade na unidade e na conciliação entre os diferentes atores exige uma capacidade político-relacional forte do Estado brasileiro, especialmente para que esta instituição não fique sujeita a interesses específicos.

No caso do Pronaf, é possível que a segmentação de sublinhas de crédito tenha sido muito mais uma tentativa de fortalecer a capacidade político-relacional do que uma elaboração com base em uma estratégia eficaz do ponto de vista do financiamento ou de estratégia operacional. Assim, em um esforço de ampliar o alcance da política a grupos específicos, ou mesmo ampliar o número de beneficiários, criou-se uma confusão entre sublinhas que têm condições muito semelhantes às linhas de crédito tradicionalmente oferecidas pelo programa.

\footnotetext{
${ }^{6}$ Cada grupo de interesse, como produtores de leite ou criadores de canários, por exemplo, pode associar-se a organizações diferentes, porque muitas vezes os interesses nesses próprios grupos são distintos. Esse exemplo, coletado em entrevista, ilustra a complexidade em conciliar os interesses.
} 


\section{Conselhos de Desenvolvimento Sustentável: lócus de participação social (pelo menos em} teoria)

Na subseção anterior, apresentaram-se alguns movimentos sociais e sua influência na criação de sublinhas de crédito no Pronaf. Para além desse espaço de movimentos organizados, que geralmente vão às ruas para manifestar suas demandas, existe um âmbito criado para o diálogo entre Estado e grupos de interesse sobre as iniciativas de desenvolvimento rural. O Conselho Nacional de Desenvolvimento Rural Sustentável (CNDRS) foi criado em 1999 e representa um primeiro canal oficial de diálogo entre o Estado, os povos rurais e outros agentes interessados. Em 2003, o CNDRS foi substituído pelo Conselho Nacional de Desenvolvimento Rural Sustentável (Condraf), incorporando as letras iniciais que identificavam as principais políticas públicas no âmbito do MDA: reforma agrária e agricultura familiar. Pode-se dizer que a criação desses conselhos é uma expressão da capacidade político-relacional; a partir de então, o Pronaf vai se consolidando em três grandes eixos: crédito, infraestrutura e formação (BIANCHINI, 2015).

Os Conselhos de Desenvolvimento Sustentável, nesse sentido, teriam o papel de lócus participativos nos diferentes níveis hierárquicos (conselhos nacionais, estaduais e municipais). A concepção de um conselho para o desenvolvimento rural, segundo Abramovay (2001), pressupõe a luta contra uma crença antiga no Brasil da existência de antagonismo entre as palavras rural e desenvolvimento. $\mathrm{O}$ autor entende que o processo de desenvolvimento rural depende de uma ação conjunta entre os diversos atores governamentais e a sociedade civil. Logo em sua criação, a gestão do Pronaf exigia a constituição de novas estruturas: conselhos de âmbito local, estadual e regional para a discussão de demandas e elaboração de projetos para que fosse possível acessar os benefícios. Assim, a maioria dos conselhos de desenvolvimento rural sustentável formou-se a partir de 1997 (ABRAMOVAY, 2001).

A existência de conselhos setoriais e temáticos em todos os níveis de atuação (nacional, estadual ou municipal) foi um instrumento importante para captar as necessidades do público-alvo das políticas públicas de desenvolvimento rural, bem como dos outros grupos de interesse envolvidos e afetados direta ou indiretamente pelas diferentes dimensões de política, e não apenas pelo Pronaf. No âmbito do Pronaf, especificamente, era necessário 
que os municípios elaborassem planos de desenvolvimento rural, que passavam por processos de aprovação nos conselhos, sobretudo no âmbito do Pronaf Infraestrutura. Esses conselhos, então, tinham grande potencial de produzir resultados positivos. Na década de 1990, funcionaram bem, principalmente porque contavam com o espírito da época de redemocratização, que também impulsionou a criação de vários conselhos em outras áreas. Contudo esse foi um avanço limitado, pois os conselhos se tornaram espaços excessivamente controlados pelo poder público municipal (DEMARCO; FAVARETO, 2003; FAVARETO, 2010).

Nos anos 2000, parte dos recursos do Pronaf Infraestrutura foi direcionado à política de desenvolvimento territorial, então é possível dizer que esse segmento do Pronaf foi regionalizado. Criaram-se colegiados de desenvolvimento territorial, que substituíram os conselhos municipais, os quais praticamente perderam sua função, constituindo estruturas inoperantes. As novas regras permitiram uma composição mais favorável à agricultura familiar nos colegiados, mas afastaram as estruturas de gestão municipal e poder público municipal, pois as prefeituras, com voz minoritária, deixaram de ter interesse nesses lócus. Esses colegiados, apesar de serem setoriais e representarem institucionalmente a agricultura familiar, não conseguem mobilizar capacidades políticas nem técnicas, pois não refletem a diversidade das forças sociais locais (FAVARETO, 2010).

Em 2019, o Condraf correu o risco de extinção pelas medidas de reformas da burocracia estatal e corte de gastos, mas foi mantido pelo Decreto $\mathrm{n}^{\circ} 9.812$ e alocado no Ministério da Mulher, da Família e dos Direitos Humanos. Apesar de não extinto, as debilidades do Conselho intensificaram-se ainda mais, processo que já vinha se reforçando desde a extinção do MDA, em 2016. Desde a extinção do MDA, o Pronaf passou a se vincular à Secretaria Especial da Agricultura Familiar e do Desenvolvimento Agrário (Sead), sob responsabilidade da Casa Civil (BRASIL, 2020, 2019).

\section{CONSIDERAÇÕES FINAIS}

A interação Estado-sociedade, que resume o significado da capacidade políticorelacional, é fundamental para garantir a legitimidade das ações do governo, o que depende amplamente da existência de regimes democráticos. No caso do Pronaf, essa capacidade 
esteve presente desde sua criação, já que foi uma resposta quase que imediata aos movimentos sociais rurais. Essa interação se estendeu ao longo do tempo e se fortaleceu, sobretudo com a ação do MDA, o que permitiu a transformação contínua da política ao longo dos anos. As transformações ora respondiam à necessidade de atender às partes interessadas politicamente relevantes, ora buscavam eficiência e eficácia, ou, ainda, o atendimento às exigências legais-burocráticas-técnicas de instituições intervenientes do setor público (como Banco Central, Banco do Brasil e organismos de controle).

De forma mais geral, este trabalho buscou ressaltar a importância dos movimentos sociais, das representações de classe e da relação do Estado com a sociedade. Espera-se contribuir com a discussão inovadora sobre as capacidades estatais, bem como com a reflexão acerca do papel dos diferentes grupos da sociedade no desenvolvimento do Pronaf. Ao mesmo tempo, coloca-se um desafio aos formuladores de políticas, que devem negociar com os diferentes atores para gerar soluções que atendam às diversas demandas, monitorando as iniciativas para que estas sejam melhoradas continuamente conforme a realidade se transforma.

Na mesma medida em que essa dimensão de capacidade é importante, é necessário que profissionais capacitados verifiquem a viabilidade das ações, para não colocar a política em risco, o que remete à necessidade de inter-relacionar e desenvolver diversos níveis de capacidade (como a burocrática, que envolve as aptidões técnicas dos agentes envolvidos na operacionalização do programa, ou a de execução, que envolve o nível estratégico de planejamento e melhoramento contínuo das iniciativas).

Por um lado, independentemente dos desafios, o resultado do desenvolvimento da capacidade político-relacional para o Pronaf não foi o enfraquecimento ou o risco para sua sustentabilidade, mas a consolidação de uma política que evoluiu ao longo do tempo, transformando-se constantemente e com ampla aceitação social, passando por diferentes governos (que, em 24 anos, tiveram objetivos e visões diferenciadas; mesmo assim, o programa foi mantido e desenvolveu-se, o que pode classificá-lo como política de Estado).

Por outro, a extinção do MDA significou a destruição de capacidades historicamente construídas, na medida em que esse órgão teve papel fundamental para o desenvolvimento e os bons resultados alcançados pelo Pronaf. $\mathrm{O}$ ambiente transformou-se radicalmente com a crise política e com o governo eleito em 2018, marcado por instabilidades, desinteresse no 
diálogo com a sociedade e apatia em relação às minorias e aos grupos vulneráveis. Apesar de o Pronaf se manter, há muitas incertezas em jogo. Nesse sentido, é importante o desenvolvimento de uma agenda de pesquisa que possa acompanhar o tema das capacidades estatais e, sobretudo, até que ponto estas podem ser resilientes às - não raramente drásticas - mudanças de orientação de governos em meio a um regime democrático.

\section{REFERÊNCIAS}

ABRAMOVAY, R. Conselhos além dos limites. Estudos avançados, São Paulo, v. 15, n. 43, p. 121-140, 2001.

APIB - Articulação dos Povos Indígenas do Brasil. Quem somos. [S.l.], 2005. Disponível em: http://apib.info/apib/. Acesso em: 23 abr. 2020.

AQUINO, J. R. de; SCHNEIDER, S. (Des)caminhos da política de crédito do Pronaf na luta contra a pobreza e a desigualdade social no Brasil rural. In: CONFERÊNCIA NACIONAL DE POLÍTICAS PÚBLICAS CONTRA A POBREZA E A DESIGUALDADE, 1., nov. 2010, Natal. Anais [...]. Natal: [s.n.], 2010. p. 1-21.

BACEN. Grupos e Linhas de Crédito PRONAF - Quadro Resumo (Plano Safra 2019/2020). [S.l.], 2019. Disponível em: https://www.bnb.gov.br/documents/165130/228956/tabela_grupos_Pronaf_19122018.pdf/9 e353e24-d3e9-39ef-2698-14f212171a61. Acesso em: 23 abr. 2020.

BARCELLOS, S. B. As Políticas Públicas para a Juventude Rural: o Pronaf Jovem em debate. Planejamento e políticas públicas, n. 48, p. 149-173, jan./jun. 2017.

BENATTI, G. S. de S. Capacidades estatais e políticas públicas: uma análise a partir da experiência do Programa Nacional de Fortalecimento da Agricultura Familiar (Pronaf) no período de 1996 a 2016. 2018. 1 recurso online (195 p.). Dissertação (mestrado) Universidade Estadual de Campinas, Instituto de Economia, Campinas, SP. Disponível em: http://www.repositorio.unicamp.br/handle/REPOSIP/331458 . Acesso em: 10 ago. 2020.

BIANCHINI, V. 20 anos do Pronaf, 1995-2015: avanços e desafios. Brasília: SAF/MDA, 2015.

BOSCHI, R. State Capabilities as a Challenge to Public Policy. In: CASTRO, A. C.; FILGUEIRAS, F. (ed.). The State in the $21^{\text {st }}$ Century. Brasília, DF: Enap, 2018. p. 337367. 
BOSCHI, R.; DINIZ, E. Uma nova estratégia de desenvolvimento? In: BRESSERPEREIRA, L. C. (org). O Que Esperar do Brasil? Rio de Janeiro: Editora FGV, 2013. p. $27-60$.

BOSCHI, R.; GAITÁN, F. Intervencionismo Estatal e as políticas de desenvolvimento na América Latina. Caderno CRH, Salvador, v. 21, n. 53, p. 305-322, maio/ago. 2008.

BRASIL. Conselho Nacional de Desenvolvimento Rural Sustentável (Condraf). Brasília, 2020. Disponível em: https://www.gov.br/mdh/pt-br/navegue-por-temas/politicaspara-mulheres/arquivo/arquivos-diversos/sobre/grupo/int_gt_cons_nac_desenv_rural. Acesso em: 06 ago. 2020.

BRASIL. Decreto $\mathbf{n}^{\mathbf{0}}$ 9.812, de 30 de maio de 2019. Altera o Decreto ${ }^{\circ} 9.759$, de 11 de abril de 2019, que extingue e estabelece diretrizes, regras e limitações para colegiados da administração pública federal. Brasília, DF: Presidência da República, [2019]. Disponível em: http://www.planalto.gov.br/ccivil_03/_Ato2019-2022/2019/Decreto/D9812.htm. Acesso em 06 ago. 2020.

BRASIL. Lei n⿳ 11.326, de 24 de julho de 2006. Estabelece as diretrizes para a formulação da Política Nacional da Agricultura Familiar e Empreendimentos Familiares Rurais. Brasília, DF: Presidência da República, 2006. Disponível em: http://www.planalto.gov.br/ccivil_03/_ato2004-2006/2006/lei/111326.htm. Acesso em: 23 abr. 2020.

CAZELLA, A. A.; MATTEI, L.; SCHNEIDER, S. Histórico, caracterização e dinâmica recente do Pronaf - Programa Nacional e Fortalecimento da Agricultura Familiar. In: SCHNEIDER, S.; KUNRATH, M.; MARQUES, P. E. (org.). Políticas públicas e participação social no Brasil rural. Porto Alegre: UFRGS, 2004. p. 21-50.

CINGOLANI, L.; CROMBRUGGHE, D. de; THOMSSON, K. State Capacity and Bureaucratic Autonomy: their impacts on development goals. Maastricht, The Netherlands: Maastricht University. 2013.

CNS - Conselho Nacional das Populações Extrativistas. Quem somos. [S.l., 20--?]. Disponível em: http://memorialchicomendes.org/quem-somos/. Acesso em: 04 dez. 2018.

CONAQ - Coordenação Nacional de Articulação das Comunidades Negras Rurais Quilombolas. Nossa história. [S.l., 20--?]. Disponível em: http://conaq.org.br/nossahistoria/. Acesso em: 23 abr. 2020.

CORRÊA, S. R. M. O Movimento dos Atingidos por Barragem na Amazônia: um movimento popular nascente de "vidas inundadas". Revista Nera, Presidente Prudente, ano 12, n. 15, p. 34-65, jul./dez. 2009. 
CORREA, V. P.; SILVA, F. F. Análise das Liberações Recentes de Recursos do Pronaf: Uma Mudança na Lógica de Distribuição? Revista Econômica do Nordeste, Fortaleza, v. 38, n. 1, p. 48-66, jan./mar. 2007.

CPP - Conselho Pastoral dos Pescadores. Movimento dos Pescadores e Pescadoras Artesanais. [S.l., 20--?]. Disponível em: https://cppnorte.wordpress.com/carta-domovimento-dos-pescadores-e-pescadoras-artesanais/. Acesso em: 23 abr. 2020.

DEMARCO, D.; FAVARETO. A. Os Conselhos Municipais de Desenvolvimento Rural entre o capital social e o bloqueio institucional. In: CONGRESSO BRASILEIRO DE SOCIOLOGIA, 11., 1-5 set. 2003, Unicamp, Campinas/SP. Anais [...]. Porto Alegre, RS: SBS, 2003. p. 1-22.

EVANS, P. The capability enhancing developmental state: concepts and national trajectories, Centro de Estudos sobre Desigualdade e Desenvolvimento (Cede/UFF), Discussion Paper, n. 63, 2011.

FARIA, J. P.; FONTANA, E. Relação Estado-sociedade no âmbito da democracia contemporânea. In: PUBLICA DIREITO. [S.l: s.n., 200-?]. 15 p. Disponível em: http://www.publicadireito.com.br/artigos/?cod=6e187996e9cc9d93. Acesso em: 23 abr. 2020 .

FAVARETO, A. Agricultores, trabalhadores: os trinta anos do novo sindicalismo rural no Brasil. Revista brasileira de ciências sociais, São Paulo, v. 21, n. 62, p. 27-45, 2006.

FAVARETO, A. As políticas de desenvolvimento territorial rural no Brasil em perspectiva - uma década de experimentações. Desenvolvimento em debate, v. 1, n. 2, p. 47-63, jan./abr. e maio/ago. 2010.

FREY, K. Políticas públicas: um debate conceitual e reflexões referentes à prática da análise de políticas públicas no Brasil. Planejamento e políticas públicas, n. 21, p. 211 259, jun. 2000.

GOMIDE, A. A. Capacidades Estatais para políticas públicas em países emergentes: (des)vantagens comparativas do Brasil. In: GOMIDE, A. de A.; BOSCHI, R. R. (ed.). Capacidades Estatais em países emergentes: o Brasil em perspectiva comparada. Rio de Janeiro: IPEA, 2016. p. 15-50.

GRISA, C.; SCHNEIDER, S. Três Gerações de Políticas Públicas para a Agricultura Familiar e Formas de Interação entre Sociedade e Estado no Brasil. Rev. Econ. Sociol. Rural, Piracicaba, SP, v. 52, supl. 1, p. 125-146, 2014.

GUANZIROLI, C. E.; BUAINAIN, A. M.; BENATTI, G. S. S.; VAHDAT V. S. The fate of family farming under the new pattern of agrarian development in Brazil. In: BUAINAIN, A. M.; LANNA, R.; NAVARRO, Z. (ed.). Agricultural Development in Brazil- The Rise of a Global Agro-food Power. USA: Routledge, 2019. p. 174-188. 
IDB - Inter-American Development Bank. The politics of policies: Economic and social progress in Latin America: 2006 Report. USA: David Rockefeller Center for Latin America Studies, 2006.

IPEA. Marcha das Margaridas: perfil socioeconômico e condições de vida das mulheres trabalhadoras do campo e da floresta. Relatório de Pesquisa. Rio de Janeiro: Ipea, 2013. Disponível em: http://transformatoriomargaridas.org.br/sistema/wpcontent/uploads/2015/02/pesquisa-ipea-marcha-das-margaridas.pdf. Acesso em: 23 abr. 2020 .

MAB. História do MAB: 20 anos de organização, lutas e conquistas. São Paulo, 2011. Disponível em: http://www.mabnacional.org.br/historia. Acesso em: 23 abr. 2020.

MEDEIROS, L. S. de; PICOLOTTO, E. L. A representação política no sindicalismo rural: antigos e novos atores. In: ENCONTRO ANUAL DA ANPOCS - Associação Nacional de Pós-Graduação e Pesquisa em Ciências Sociais, 40., Caxambu, MG, 2016. Anais [...]. São Paulo: Anpocs, 2016. p. 1-30. Disponível em: https://anpocs.com/index.php/papers-40encontro/st-10/st34-3/10505-a-representacao-politica-no-sindicalismo-rural-antigos-enovos-atores/file. Acesso em: 23 abr. 2020.

MENDONÇA, L. Transformando burocracias para financiar os mais pobres: a evolução do Pronaf Crédito Grupo B. Revista do Serviço Público, Brasília, v. 59, n. 2, p. 187-220, abr./jum. 2008.

MNI - Mobilização Nacional Indígena. Nossa história não começa em 1988. [S.l.], 2017. Disponível em: https://mobilizacaonacionalindigena.wordpress.com/. Acesso em: 23 abr. 2020.

NAVARRO, Z. A agricultura familiar no Brasil: entre a política e as transformações da vida econômica. In: FILHO, J. E. R.; GASQUES, J. G.; NAVARRO, Z. (org.). A agricultura brasileira: desempenho, desafios e perspectivas. Brasília: IPEA, 2010. Capítulo 7, p. 185-209.

NAVARRO, Z.; PEDROSO, M. T. M. Agricultura familiar: é preciso mudar para avançar. Brasília, DF: Embrapa Informação Tecnológica, 2011. (Texto para Discussão.)

PIRES, M. J. de S. Contradições em processo: um estudo da estrutura e evolução do Pronaf de 2000 a 2010. Brasília: Rio de Janeiro: Ipea, 2013. (Texto para discussão, 1.914.)

QUEIROZ, R. G. Visibilidade e protagonismo dos pescadores e pescadoras do Brasil. Extramurus - Revista de Extensão da UNIVASF, v. 3, n. 2, p. 244-250, jul. 2015. Disponível em: http://www.periodicos.univasf.edu.br/index.php/extramuros/article/viewFile/747/476. Acesso em: 04 dez. 2018. 
SCARTASCINI, C.; TOMMASI, M. Government Capabilities in Latin America: Why They Are So Important, What We Know about Them, and What to Do Next. [S.l.]: IDB, Jan. 2014.

SCHNEIDER, S. Situando o desenvolvimento rural no Brasil: o contexto e as questões em debate. Revista de economia política, v. 30, n. 3, p. 511-531, 2010.

SILVA, A. R. F. da. Políticas públicas para comunidades quilombolas: uma luta em construção. Política \& Trabalho, Joao Pessoa, v. 1, n. 48, p. 115-128, 2018.

SOUZA, C. Capacidade burocrática no Brasil e na Argentina: quando a política faz a diferença. In: GOMIDE, A. de A.; BOSCHI, R. R. (ed.). Capacidades Estatais em países emergentes: o Brasil em perspectiva comparada. Rio de Janeiro: IPEA, 2016. p. 51-104.

SOUZA, M. A. de. O PRONAF e os povos indígenas. In: VERDUM, R. (org.). Assistência técnica e financeira para o desenvolvimento indígena: possibilidades e desafios para políticas públicas. Rio de Janeiro: Contra Capa Livraria, 2005. p. 117-138.

TRANSFORMATÓRIO DAS MARGARIDAS. O que é a Marcha das Margaridas. [S.l., 20--?]. Disponível em: http://transformatoriomargaridas.org.br/?page_id=139. Acesso em: 23 abr. 2020. 